Available online at: https://proceeding.researchsynergypress.com/index.php/cpmhs/index

RSF Conference Series: Medical and Health Science

e-ISSN (to be processed) / p-ISSN (to be processed)

Volume 1 Number 1 (2021): 120-126

\title{
Factor Affecting Nutritional Status among Students in Pandemic Period: Sleep Duration, Physical Activity, and Knowledge of Balanced Nutrition
}

\author{
Meta Maulida Damayanti' ${ }^{1}$ Yuniarti ${ }^{2}$ \\ ${ }^{1}$ Pathology Anatomy Department, Faculty of Medicine, Universitas Islam Bandung, Indonesia; \\ ${ }^{2}$ Anatomy Department, Faculty of Medicine Universitas Islam Bandung, Indonesia.
}

\begin{abstract}
The pandemic situation due to COVID-19, the coronavirus disease that has spread throughout the world, has an impact on all aspects, including nutritional needs, especially in children. This study aimed to analyze the relationship between nutritional status with sleep duration, physical activity, and knowledge of balanced nutrition among a group of students in a pandemic period. The research is observational analytic cross-sectional conducted in Manarul Huda Islamic Boarding School Bandung to 39 students. Body Mass Index (BMI) is used to assess nutritional status. Knowledge of balanced nutrition through a validated questionnaire; sleep duration, which is obtained from the question how long do you need to sleep in 1 day; and physical activity rated from the duration of exercise in 1 week. Statistical analysis was performed using SPSS version 23.0. The relationship between categorical variables was assessed using the Chi-square independence test. The result shows that nutritional status among students has good interaction with sleep duration, physical activity, and knowledge of balanced nutrition with a value of $p<0.05$. In conclusion, this study states nutritional status determines the quality of life. Sleep duration, exercise, and knowledge of balanced nutrition are factors that can determine a person's nutritional status. Further analysis is needed regarding other factors that influence nutritional status.
\end{abstract}

Keywords: Nutritional Status, Sleep Duration, Physical Activity, Nutritional Knowledge

This is an open access article under the CC-BY-NC license

\section{INTRODUCTION}

The pandemic conditions have resulted in changes in the lifestyle of the general public, one of which is school-age children. Children in the period of optimal growth are required to adapt to this condition. Social restrictions implemented to prevent transmission, on the one hand, will have an impact on reduced activity, sleep patterns, and ultimately on nutritional status. This phenomenon needs special attention, how is the condition of nutritional status with social limitations and limited access to health services. This study aimed to analyze the relationship between nutritional status with sleep duration, physical activity, and knowledge of balanced nutrition among a group of students in a pandemic period.

\section{LITERATURE REVIEW}

The current pandemic situation is caused by COVID-19, a coronavirus disease that is spreading throughout the world. Countermeasures are taken to reduce the widespread impact, especially on children. Children experience changes and disturbances both socially, educationally, and even in general health, including the development of nutritional status. During an ongoing pandemic, it is important to identify children's nutritional intake and the factors that influence it, such as sleep duration, exercise, and

Corresponding author

Meta Maulida Damayanti, meta.fkunisba@gmail.com

DOI: (to be processed)

Research Synergy Foundation 
balanced nutritional intake. Nutrition has been a vital component of human health, life, and brain development through the ages. Malnutrition could exacerbate the effects of COVID-19. Malnutrition is currently an important issue among children in Indonesia and even globally, especially in developing countries. (Bharthi et al., 2017, Maehara et al., 2019, Fore et al., 2020)

The nutrients we eat are needed for tissue growth and regeneration, producing the energy needed for metabolic processes. Nutritional knowledge covers all processes towards a good balance between body needs and nutritional intake, at the right time and in the right proportion, at the level of cells, tissues, organs, and the whole body. Knowledge of balanced nutrition is needed to meet important nutritional needs, sleep duration affecting of the biological and behavioral mechanism of body, physical activity influences on physical condition, health status, and well-being of life. Simple screening can be assessed to see a person's nutritional status by calculating body mass index (BMI). (Lean, 2019, Rosi et al., 2017, Lee, 2017, Mani, 2014, Frank et al., 2017)

Lockdown is done to cut off the transmission of the virus but causes changes in physical activity and sleep patterns. During social restrictions, activities carried out outside are very limited as a result, a lot of time is spent at home. Decreased physical activity is usually accompanied by poor sleep patterns. This condition is quite worrying, especially among children, because it will affect general health. Physical activity and regular exercise provide many health benefits. These benefits vary according to volume and need as reflected in intensity, durability, and frequency; there is a significant linear relationship between physical activity and health status, the increase in physical activity and fitness results in an increase in health status. (Hills et al., 2015). Sleep is very important for the health and well-being of children. Sleep characteristics of children such as sleep duration, time, quality, and variability were increasingly associated with health conditions. (Matricciani et al., 2019) There was an impact of habits on sleep duration and variations in sleep duration, and identified that the duration of sleep habits was shorter and greater variation in duration was independently associated with an increase in BMI. (Xu et al., 2018)

The research aim is to analyze the relationship between nutritional status with sleep duration, physical activity, and knowledge of balanced nutrition among students in the pandemic period.

\section{RESEARCH METHODOLOGY Study Design}

This study is an analytic observational study with a cross-sectional design that was conducted at the Manarul Huda Islamic Boarding School in March 2021.

Subjects are all of the students who meet the criteria. The inclusion criteria were: students who were registered at the Islamic boarding school in 2021, did not leave the dormitory during the pandemic, and were in good health, while the exclusion criteria were respondents who were not present at the time of data collection.

\section{Data Collection}

For data collection, the researcher visited the study setting and obtained the permission of the principal of the school. Data were collected using BMI calculations, data personal of sleep duration and physical activity, and knowledge of balanced nutrition questionnaires (Supplementary File Meta D, 2021c). BMI calculations were used to assess nutritional status. The independent variable in this study was sleep duration which was obtained from the question of how much sleep is needed in 1 day; physical activity obtained from the duration of exercise in 1 week; and knowledge of balanced nutrition through a validated questionnaire. 
Measurement of height and weight was taken, and then the weight of BMI $(\mathrm{kg})$ / height (m2) was calculated. Measurements are based on the WHO format into underweight ( $\leq 18.4 \mathrm{~kg} / \mathrm{m} 2)$, normal (18.5$24.9 \mathrm{~kg} / \mathrm{m} 2$ ), overweight (25.0-29.9 kg / m2) and obese ( $\geq 30.0 \mathrm{~kg} / \mathrm{m} 2)$.(Lim et al., 2017). Bodyweight is measured using a body scale. The scale was checked for accuracy and calibrated prior to the commencement of the study. Respondents were asked to remove heavy clothing, shoes, jackets, and other heavy accessories. After the scale is turned on and looks zero, the respondent is asked to stand on the scale. The weight is then recorded. The procedure was repeated 2 to 3 times, and measurements were recorded by calculating the average. Height is measured using a portable body meter. Respondents were asked to stand in an anatomical position. The respondent's head is positioned in the Frankfort area horizontally, and once the correct position is reached, the head plate is lowered so that it touches the top of the respondent's head. This procedure is repeated, and measurements are recorded by calculating the average.

Sleep time in one day consists of 4 answer choices; > eight hours, six to eight hours, four to five hours, and less than four hours. Exercise in one week consists of four answer choices; > five days per week, three to 4 times a week, one to two times a week, and no exercise. Knowledge of balanced nutrition questionnaire consisted of 16 items that were scored based on correct answer gets the point 1 , wrong or no answer gets the point 0 .

\section{Data Analysis}

Statistical analysis was performed using SPSS 23.0 version. The relationship between categorical variables was assessed by means of the Chi-square independence test. The level of significance was set at $\mathrm{p}<0.05$. The confidence interval (CI) at $95 \%$ of the odds ratio (OR) and the p-value of the relationship were obtained to make conclusions in the study population.

\section{Ethical Clearance}

Approval to conduct research was obtained from the Research Health Ethics Committee from a University (108/KEPK-Unisba/XII/2020). The author obtained the consent of Manarul Huda Islamic Boarding School for doing this research. Prior to the study, all respondents had been given information about the objectives and benefits of the study, and all respondents signed written informed consent.

\section{FINDINGS AND DISCUSSION Finding}

A total of 39 subjects were included in this study, 31 girls and eight boys, with an age range of 9-15 years.

Table 1. Relationship of nutritional status with sleep duration

\begin{tabular}{lccccccc}
\hline \multirow{2}{*}{ Variable } & \multicolumn{6}{c}{ Nutritional status } & P- \\
\cline { 2 - 7 } & \multicolumn{2}{c}{ Underweight } & \multicolumn{2}{c}{ Normal } & Overweight & value*) \\
\cline { 2 - 7 } & $\mathbf{n}$ & $\mathbf{\%}$ & $\mathbf{n}$ & $\mathbf{\%}$ & $\mathbf{n}$ & $\mathbf{\%}$ & \\
\hline $\begin{array}{l}\text { Sleep duration in a day } \\
\text { (hour) }\end{array}$ & & & & & & & $\mathbf{0 . 0 2 7}$ \\
$\quad<4$ & 11 & 61,1 & 2 & 11,2 & 5 & 27,8 & \\
$4-5$ & 4 & 36,4 & 6 & 54,5 & 1 & 9,1 & \\
$6-8$ & 2 & 33,3 & 4 & 66,7 & 0 & 0,0 & \\
$>8$ & 1 & 25,0 & 3 & 75,0 & 0 & 0,0 & \\
\hline
\end{tabular}


Sleep duration of fewer than 4 hours mostly has less nutrition (underweight) as many as 11 people (61.1\%), and students who have a sleep duration of $>8$ hours mostly have normal nutrition $(75.0 \%)$. (Table 1)

Table 1 also shows that the results of the Chi-Square Test analysis at the 95\% confidence level show that statistically, there is a significant relationship between sleep duration and body mass index among students with $\mathrm{p}$-value $=0.027$ ( $\mathrm{p}$-value $\leq 0.05$ ).

Table 2. Relationship of nutritional status with physical activity

\begin{tabular}{lccccccc}
\hline \multirow{2}{*}{ Variable } & \multicolumn{6}{c}{ Nutritional status } & P- \\
\cline { 2 - 7 } & \multicolumn{2}{c}{ Underweight } & Normal & Overweight & value*) \\
\cline { 2 - 7 } & $\mathbf{n}$ & $\mathbf{\%}$ & $\mathbf{n}$ & $\mathbf{\%}$ & $\mathbf{n}$ & $\mathbf{\%}$ & \\
\hline Physical activity in a & & & & & & & $\mathbf{0 . 0 0 5}$ \\
week & 4 & 80,0 & 1 & 20,0 & 0 & 0,0 & \\
$\quad 5$ & 5 & 50,0 & 5 & 50,0 & 0 & 0,0 & \\
$3-4$ & 9 & 47,4 & 8 & 42,1 & 2 & 10,5 & \\
$1-2$ & 0 & 0,0 & 1 & 20,0 & 4 & 80,0 & \\
$\quad$ No activity & & & & & &
\end{tabular}

Students who have physical activity/sports more than five days in 1 week mostly have less nutrition (underweight) as $80.0 \%$ and students who have no physical activity/exercise Most of the body in 1 week have more nutrition as many as $80.0 \%$. (Table 2) The results of the Chi-Square Test analysis at the $95 \%$ confidence level show that statistically, there is a significant relationship between physical activity/exercise in 1 week and body mass index among students with $\mathrm{p}=0.005$. ( $\mathrm{p}$-value $\leq 0.05$ ).

Table 3. Relationship of nutritional status with knowledge of balanced nutrition

\begin{tabular}{|c|c|c|c|c|c|c|c|}
\hline \multirow[t]{3}{*}{ Variable } & \multicolumn{6}{|c|}{ Nutritional status } & \multirow{3}{*}{$\begin{array}{c}\text { P- } \\
\text { value }^{*} \text { ) }\end{array}$} \\
\hline & \multicolumn{2}{|c|}{ Underweight } & \multicolumn{2}{|c|}{ Normal } & \multicolumn{2}{|c|}{ Overweight } & \\
\hline & $\mathbf{n}$ & $\%$ & $\mathbf{n}$ & $\%$ & $\mathbf{n}$ & $\%$ & \\
\hline Knowledge & & & & & & & 0.040 \\
\hline Not Good & 6 & 28,6 & 10 & 47,6 & 5 & 23,8 & \\
\hline Good & 12 & 66,7 & 5 & 27,8 & 1 & 5,6 & \\
\hline Attitude & & & & & & & 0.010 \\
\hline Negative & 3 & 25,0 & 4 & 33,3 & 5 & 41,7 & \\
\hline Positive & 15 & 55,6 & 11 & 40,7 & 1 & 3,7 & \\
\hline Practice & & & & & & & 0.016 \\
\hline Poor & 13 & 68,4 & 5 & 26,3 & 1 & 5,3 & \\
\hline Good & 5 & 25,0 & 10 & 50,0 & 5 & 25,0 & \\
\hline
\end{tabular}

The number of students who have more nutrition (overweight) with knowledge of malnutrition is five people (23.8\%) more than students who are overweight with good knowledge as many as one person (5.6\%). Table 3 also shows that there is a significant relationship between knowledge of nutrition and body mass index among students with a p-value $=0.040$ (p-value $\leq 0.05$ ). Students who have overweight with negative attitudes towards nutrition are five people (41.7\%) more than students who are overweight with positive attitudes as much as one person (3.7\%). In addition, it was also found that students who had negative attitudes towards nutrition had underweight as many as three people (25.0\%). There is a significant relationship between attitudes towards nutrition and body mass index among students with $\mathrm{p}$ - 
value $=0.010$ (p-value $\leq$ 0.05). 13 students (68.4\%) who have bad behavior with malnutrition (68.4\%). Nutrition and body mass index in students have a good interaction with $p$-value $=0.016$ ( $p$-value $\leq 0.05$ ).

\section{Discussion}

In this study, we involved a group of 38 students from Islamic boarding schools (31 girls and eight boys). Many factors affect nutritional status. A significant interaction was apparent for the relationship between nutritional status with sleep duration, physical activity, and level of knowledge about balanced nutrition. Nutritional status affects how the immune response to disease. (Ferreira et al., 2015). Parameters of sleep duration, level of physical activity, knowledge of balanced nutritional intake, and anthropometry were measured to assess the relationship between each other. (Grygiel-Górniak et al., 2016) In addition, malnutrition is considered a serious problem that affects children's learning abilities and causes reduced concentration at school. Malnutrition is a major public health challenge that affects school academic achievement. Previous studies conducted in various regions have shown that malnutrition is common among children; reported stunting ranging and quite high underweight. Malnutrition is a serious disease problem and very common in developing countries, including Indonesia. (Bhattacharya et al., 2019)

This study states that body mass index with underweight category is closely related to less sleep duration. Sleep plays an important role in determining good health and well-being. Proper and quality sleep helps protect physical and mental health and improves the quality of life. Especially children and adolescents have a physiological need for more sleep, and inadequate sleep quantity and quality are associated with significant problems, one of which is nutritional status. Similar to other studies, we found that sleep is very important for health and quality of life. Children's sleep characteristics such as duration, timing, quality, and variability of sleep are increasingly associated with various health outcomes. (Matricciani et al., 2019) Similar to another study that sleep deprivation causes many problems in the school environment, where suboptimal sleep duration and sleep disturbances are associated with decreased academic functioning, including difficulty concentrating on studies and allowing frequent absences from school due to fatigue. (Kim et al., 2019) Longer sleep duration is associated with lower adiposity indicators, better emotion regulation, better academic performance, and better quality of life/well-being. Short sleep duration is a risk factor or a marker of vulnerability to obesity in children. (Miller et al., 2018, Lim et al., 2017)

An association was strongest between the duration of physical activity and BMI. Respondents who did not exercise had a higher body mass index than those who exercised. Physical activity with the right frequency increases the body's ability to properly care for vital organs, good metabolism, and body homeostasis. However, excessive exercise without adequate intake will affect nutritional status. Regular physical activity, even with a relatively small volume of physical activity, can effectively improve health and reduce the risk of chronic disease. (Rhodes et al., 2017) Similar to other studies that there is a significant increase in provider and parent knowledge about nutrition and physical activity, improvement in central level policies, and changes in child levels in children's BMI after being given interventions such as health education, etc. (Alkon et al., 2014)

Respondents with a good level of knowledge, attitude, and behavior towards balanced nutritional needs have a normal BMI. The level of knowledge, attitude, and behavior of balanced nutrition greatly influence habits in fulfilling nutritional intake. The ability to sort out healthy and nutritious intake leads to a good diet so that they have good nutritional status. Another study conducted by Tamara Tabbakh et al. analyzed the importance of maternal nutritional knowledge and the mediating effect of the home 
RSF Conference Series: Medical and Health Science, Vol. 1 (1), 120-126

Factor Affecting Nutritional Status among Students in Pandemic Period: Sleep Duration, Physical Activity, and Knowledge of Balanced Nutrition

Meta Maulida Damayanti, Yuniarti

environment on adolescent diet quality (Tabbakh and Freeland-Graves, 2016). Knowledge of children's nutrition about food intake may be as important as knowledge of caregivers or parents about good nutrition. (Asakura et al., 2017)

Limitations are recognized, due to the pandemic period, there is a risk of transmitting Covid-19 if primary data collection is in the form of direct doing face-to-face research for a long time. Further research can add other variables such as diet and family history of nutritional status.

\section{CONCLUSION AND FURTHER RESEARCH}

Nutritional status determines the quality of life. Sleep duration, exercise, and knowledge of balanced nutrition are factors that can determine a person's nutritional status. Further analysis is needed regarding other factors that influence nutritional status, especially in the pandemic period.

\section{Data Analysis}

Figshare: Nutritional status

https://doi.org/10.6084/m9.figshare.16547934.(Meta, 2021a)

Figshare: Informed consent

https://doi.org/10.6084/m9.figshare.16548036. (Meta, 2021b)

Figshare: Questionnaire of balanced nutrition

https://doi.org/10.6084/m9.figshare.16548048. (Meta, 2021c)

\section{REFERENCES}

Alkon, A., Crowley, A. A., Neelon, S. E. B., Hill, S., Pan, Y., Nguyen, V., Rose, R., Savage, E., Forestieri, N., Shipman, L. \& Kotch, J. B. 2014. Nutrition And Physical Activity Randomized Control Trial In Child Care Centers Improves Knowledge, Policies, And Children's Body Mass Index. Bmc Public Health, 14, 215.

Asakura, K., Todoriki, H. \& Sasaki, S. 2017. Relationship Between Nutrition Knowledge And Dietary Intake Among Primary School Children In Japan: Combined Effect Of Children's And Their Guardians' Knowledge. Journal Of Epidemiology, 27, 483-491.

Bharthi, K., Ghritlahre, M., Das, S. \& Bose, K. 2017. Nutritional Status Among Children And Adolescents Aged 6-18 Years Of Kolam Tribe Of Andhra Pradesh, India. Anthropological Review, 80, 153.

Bhattacharya, A., Pal, B., Mukherjee, S. \& Roy, S. K. 2019. Assessment Of Nutritional Status Using Anthropometric Variables By Multivariate Analysis. Bmc Public Health, 19, 1045.

Ferreira, E. D. A., Alexandre, M. A., Salinas, J. L., De Siqueira, A. M., Benzecry, S. G., De Lacerda, M. V. G. \& Monteiro, W. M. 2015. Association Between Anthropometry-Based Nutritional Status And Malaria: A Systematic Review Of Observational Studies. Malaria Journal, 14, 346.

Fore, H. H., Dongyu, Q., Beasley, D. M. \& Ghebreyesus, T. A. 2020. Child Malnutrition And Covid-19: The Time To Act Is Now. The Lancet, 396, 517-518.

Frank, S., Gonzalez, K., Lee-Ang, L., Young, M. C., Tamez, M. \& Mattei, J. 2017. Diet And Sleep Physiology: Public Health And Clinical Implications. Frontiers In Neurology, 8. 
Grygiel-Górniak, B., Tomczak, A., Krulikowska, N., Przysławski, J., Seraszek-Jaros, A. \& Kaczmarek, E. 2016. Physical Activity, Nutritional Status, And Dietary Habits Of Students Of A Medical University. Sport Sciences For Health, 12, 261-267.

Hills, A. P., Street, S. J. \& Byrne, N. M. 2015. Chapter Three - Physical Activity And Health: "What Is Old Is New Again". In: Henry, J. (Ed.) Advances In Food And Nutrition Research. Academic Press.

Kim, J., Noh, J.-W., Kim, A. \& Kwon, Y. D. 2019. Relationships Between Sleep Patterns, Health Risk Behaviors, And Health Outcomes Among School-Based Population Of Adolescents: A Panel Analysis Of The Korean Children And Youth Panel Survey. International Journal Of Environmental Research And Public Health, 16.

Lean, M. E. J. 2019. Principles Of Human Nutrition. Medicine, 47, 140-144.

Lee, J. 2017. Sleep Duration's Association With Diet, Physical Activity, Mental Status, And Weight Among Korean High School Students, Hec Press.

Lim, J. U., Lee, J. H., Kim, J. S., Hwang, Y. I., Kim, T.-H., Lim, S. Y., Yoo, K. H., Jung, K.-S., Kim, Y. K. \& Rhee, C. K. 2017. Comparison Of World Health Organization And Asia-Pacific Body Mass Index Classifications In Copd Patients. International Journal Of Chronic Obstructive Pulmonary Disease, 12, 2465-2475.

Maehara, M., Rah, J. H., Roshita, A., Suryantan, J., Rachmadewi, A. \& Izwardy, D. 2019. Patterns And Risk Factors Of Double Burden Of Malnutrition Among Adolescent Girls And Boys In Indonesia. Plus One, 14, E0221273.

Mani, G. 2014. Assessment Of Body Mass Index And Its Associated Nutritional Factors Among Undergraduate Medical Students In Tamil Nadu, India: A Cross-Sectional Study. Journal Of Pioneering Medical Sciences, 4.

Matricciani, L., Paquet, C., Galland, B., Short, M. \& Olds, T. 2019. Children's Sleep And Health: A Meta-Review. Sleep Medicine Reviews, 46, 136-150.

Meta, D. 2021a. Data Of Nutritional Status And Affecting Factors.

Meta, D. 2021b. Informed Consent.

Meta, D. 2021c. Questionnaire Of Balanced Nutrition.

Miller, M. A., Kruisbrink, M., Wallace, J., Ji, C. \& Cappuccio, F. P. 2018. Sleep Duration And Incidence Of Obesity In Infants, Children, And Adolescents: A Systematic Review And Meta-Analysis Of Prospective Studies. Sleep, 41.

Rhodes, R. E., Janssen, I., Bredin, S. S. D., Warburton, D. E. R. \& Bauman, A. 2017. Physical Activity: Health Impact, Prevalence, Correlates And Interventions. Psychology \& Health, 32, $942-$ 975.

Rosi, A., Calestani, M. V., Parrino, L., Milioli, G., Palla, L., Volta, E., Brighenti, F. \& Scazzina, F. 2017. Weight Status Is Related With Gender And Sleep Duration But Not With Dietary Habits And Physical Activity In Primary School Italian Children. Nutrients, 9, 579.

Tabbakh, T. \& Freeland-Graves, J. H. 2016. The Home Environment: A Mediator Of Nutrition Knowledge And Diet Quality In Adolescents. Appetite, 105, 46-52.

Xu, X., Conomos, M. P., Manor, O., Rohwer, J. E., Magis, A. T. \& Lovejoy, J. C. 2018. Habitual Sleep Duration And Sleep Duration Variation Are Independently Associated With Body Mass Index. International Journal Of Obesity, 42, 794-800. 